\title{
TRINTA E DOIS ANOS DO PROGRAMA DE MELHORAMENTO GENÉTICO DO FEIJOEIRO COMUM EM MINAS GERAIS
}

\author{
Thirty two years of common bean breeding in Minas Gerais state
}

\author{
José Wilacildo de Matos', Magno Antonio Patto Ramalho², Ângela de Fátima Barbosa Abreu ${ }^{3}$
}

\begin{abstract}
RESUMO
Conduziu-se este trabalho, com o objetivo de proceder à análise crítica do Programa de melhoramento genético do feijoeiro comum em Minas Gerais nos últimos 32 anos com ênfase nas implicações da interação linhagens x ambientes, além de avaliar se houve progresso genético. Para isso, foram utilizados dados de 169 experimentos conduzidos no período de 1974 a 2004 e que envolveram 16 locais e três safras. A média da cultivar Carioca, comum em todos os experimentos, foi utilizada como estimador do efeito ambiental e a média das cinco melhores linhagens sob avaliação de cada biênio, como efeito fenotípico. A diferença entre essas duas médias forneceu o desvio genético. O coeficiente de regressão linear entre desvio genético Y (variável dependente) e o biênio X (variável independente) forneceu a estimativa do progresso genético. As interações linhagens x safras e linhagens x anos foram, na maioria dos casos, significativas, contudo, suas contribuições para a variação total foram inferiores a de linhagens x locais. Desse modo, fica clara a necessidade de que os experimentos sejam conduzidos em um maior número de locais. O programa de melhoramento genético do feijoeiro da UFLA tem sido eficiente e tem obtido linhagens com menor risco de adoção.
\end{abstract}

Termos para indexação: Progresso Genético, Interação Genótipos x Ambientes, Índice de Confiança, Phaseolus vulgaris L.

\begin{abstract}
The objective of the present work was to make critical analysis of the dry bean genetic breeding program in Minas Gerais in the last 32 years by lines x environments interactions and genetic progress evaluations. Data from 169 experiments conducted from 1974 to 2004 in 16 locations and three seasons per year were used. The average of the cultivar Carioca, test in all experiments, was used as indicator of environmental variation; and the average of the five best lines, under evaluation in each biennium, was used as indicator of phenotypic variation. The difference between these two averages was used as genetic deviation. Genetic progress was estimated by linear regression coefficient between genetic deviation Y (dependent variable) and biennium X (independent variable). The interactions among lines $\mathrm{x}$ seasons and lines $\mathrm{x}$ years were significant in most cases, however, their contributions to the total variation were inferior to the lines $x$ locations. Thus, it was necessary to conduct experiments in a larger number of locations. The common bean breeding program at UFLA has been efficient and has selected lines with less risk for adoption for farmers.
\end{abstract}

Index terms: Genetic Progress, Genotypes x Environments Interaction, Reliability Index, Phaseolus vulgaris L.

(Recebido em 10 de janeiro de 2006 e aprovado em 9 de março de 2007)

\section{INTRODUÇÃO}

Os programas de melhoramento genético do feijoeiro comum no Brasil são restritos e concentrados, predominantemente no setor público. Os primeiros programas iniciaram por volta de 1930 , mas a maioria começou suas atividades a partir de 1970 (VOYSEST, 2000). Um desses programas é o da Universidade Federal de Lavras (UFLA), que começou em 1971.

Qualquer programa de melhoramento, especialmente aqueles com recursos limitados, deve, periodicamente, ser submetido à análise crítica com relação às suas contribuições e em busca de novas metodologias que possam melhorar a sua eficácia. Neste contexto, a estimativa do progresso genético constitui uma das opções utilizadas nessa análise (ABREU et al., 1994; SOARES et al., 2005). Outra opção é verificar se as técnicas experimentais têm possibilitado detectar diferenças entre as linhagens avaliadas. Adicionalmente, deve-se quantificar a interação das linhagens x ambientes, safras, locais e anos, com a finalidade de propor alternativas para atenuar o seu efeito.

Para obter essas informações relativas ao programa de melhoramento da UFLA, foram utilizados dados das avaliações de linhagens de feijoeiro comum, conduzidas durante o período de 1974 a 2004. Foram obtidas estimativas

\footnotetext{
'Engenheiro Agrônomo, Doutor em Genética e Melhoramento de Plantas - Geneze Sementes LTDA - Rodovia Br 040, Km 43,5, Nossa Senhora de Fátima Paracatu, MG - wilacildo@yahoo.com.br

'Engenheiro Agrônomo, Doutor em Genética e Melhoramento de Plantas - Departamento de Biologia/DBI - Universidade Federal de Lavras/UFLA - Cx. P. 3037 - 37200-000 - Lavras, MG - magnoapr@ufla.br

${ }^{3}$ Engenheira Agrônoma, Doutora em Genética e Melhoramento de Plantas - Departamento de Biologia/DBI - Embrapa Arroz e Feijão/UFLA - Cx. P. 3037 37200-000 - afbabreu@ufla.br
} 
do progresso genético para avaliar o sucesso ou não do programa e a magnitude das diferentes interações de linhagens com os fatores ambientais.

\section{MATERIAL E MÉTODOS}

Foram utilizados dados de avaliação de linhagens conduzidas pelo programa da UFLA no período de 1974 a 2004, envolvendo 169 experimentos. Os locais desses experimentos se concentraram $(91 \%)$ nas regiões Sul do Estado de Minas, predominantemente nos municípios de Lavras $\left(21^{\circ} 14^{\prime} \mathrm{S}\right.$ de latitude e $44^{\circ} 59^{\prime}$ ' $\mathrm{W}$ de longitude, altitude

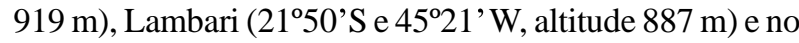

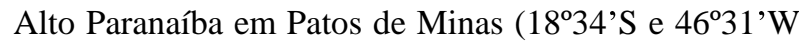
altitude $832 \mathrm{~m}$ ). Os experimentos foram conduzidos nas safras "das águas" (semeadura de outubro a novembro) a partir de 1974, "da seca" (semeadura de fevereiro a março) após 1982 e "do outono-inverno" (semeadura de julho a agosto) a partir de 1989 .

Foram avaliadas de 15 a 42 linhagens. A cada biênio as linhagens foram substituídas parcialmente até 1993 e totalmente a partir de então. Utilizaram-se testemunhas nos experimentos, sendo a cultivar Carioca comum a todos eles. Outras testemunhas utilizadas em alguns biênios foram as cultivares Carioca-MG, Milionário, Emgopa-201-Ouro, Pérola, BRSMG Talismã e Ouro Negro. No total foram avaliadas 320 linhagens não incluindo as testemunhas.

Até 1989, foi adotado o delineamento de blocos casualizados com número de repetições variando de três a cinco. Após 1989, o delineamento utilizado foi o látice quadrado parcialmente balanceado com três repetições. Até 2001, as parcelas sempre foram constituídas de duas linhas de cinco metros com 15 sementes por metro. Posteriormente, a parcela passou a ser de duas linhas de quatro metros. Foram efetuadas análises de variância da produtividade de grãos por ambientes. Posteriormente, realizaram-se análises conjuntas por biênio, utilizando o PROC GLM do SAS.

Como a cultivar Carioca esteve presente em todos os experimentos, foi obtido o seu desempenho médio por biênio. $\mathrm{O}$ mesmo procedimento foi adotado em relação às linhagens de cada biênio. Para a obtenção da estimativa do progresso genético, adotou-se metodologia semelhante a apresentada por Abreu et al. (1994). Para isso foi estimado o desvio genético do biênio $\mathrm{j}\left(\mathrm{d}_{\mathrm{j}}\right)$ pela diferença entre a produtividade média de grãos das cinco melhores linhagens avaliadas $\left(\overline{\mathrm{L}}_{\mathrm{j}}\right)$,no biênio j e a média da 'Carioca' $\left(\overline{\mathrm{C}}_{\mathrm{j}}\right)$, no respectivo biênio, ou seja: $d_{j}=\bar{L}_{j}-\bar{C}_{j}$. De posse do valor de $d_{j}$, foi estimado o coeficiente de regressão linear (b) utilizando como variável independente o número de biênios e dependente a estimativa de $d_{j}$. Os b's das equações de regressão foram testados pelo teste t, utilizando-se o erro médio dos experimentos envolvidos.

A estimativa do progresso genético (PG) foi obtida pelo estimador: $P G=\left(\frac{b_{j}}{\bar{L}_{j}} \times 100\right) / 2 ;$ em que $\overline{\mathrm{L}}_{\mathrm{j}}$, corresponde à estimativa do desempenho médio das linhagens avaliadas no primeiro biênio. Esta estimativa foi obtida por meio da equação de regressão linear, tendo o número dos biênios como variável independente $(\mathrm{X})$ e a produtividade média de grãos das linhagens variável dependente ( $\overline{\mathrm{L}}$ ).

Foi utilizada a metodologia de Annicchiarico (1992) para avaliar o risco de adoção e o índice de confiança das linhagens. Para isso, utilizou-se o seguinte estimador: $\mathrm{I}_{\mathrm{i}}=\overline{\mathrm{Y}}_{\mathrm{i} .}-\mathrm{Z}_{(1-\alpha)} \mathrm{s}_{\mathrm{i}}$, em que $\mathrm{I}_{\mathrm{i}}$ : índice de confiança em percentagem da cultivar; $\mathrm{Y}_{\mathrm{i}}$ : média geral da linhagem i em percentagem da 'Carioca'. Para cada ambiente do biênio, foi estimada a percentagem média das linhagens em relação à 'Carioca'; $Z_{(1-\alpha)}$ : percentil (1- $\alpha$ ) em função da distribuição normal acumulada; $\alpha$ : nível de significância. Foi adotado $\alpha=0,25$; s: desvio padrão dos valores percentuais, entre os biênios, da cultivar i.

\section{RESULTADOS E DISCUSSÃO}

No início, o programa da UFLA avaliou linhagens locais (“crioulas"). Até próximo de 1980, a ênfase foi para feijões de cores, especialmente, 'Roxo', 'Rosinha', 'Pardo' e 'Pintado'. Posteriormente, as pesquisas concentraramse em feijões do tipo 'Carioca'. É oportuno enfatizar que a cultivar Carioca recomendada pelo IAC em 1969 (ALMEIDA et al., 1971) foi testada pela UFLA já em 1969. A partir de 1980, a atenção foi direcionada a esse tipo de grão.

Uma das ênfases do programa foi a resistência aos patógenos. No início, o vírus do mosaico comum recebeu grande atenção. Posteriormente, como as linhagens 'Carioca' são resistentes a esse vírus, praticamente não houve mais relatos da sua ocorrência. O contrário ocorreu com a mancha angular (Phaeoisariopsis griseola), que não tinha grande importância até meados de 1990, porém, a partir de então, a obtenção de resistência a esse patógeno foi prioritária. No caso de antracnose (Colletotrichum lindemuthianum), atenção foi dada durante todo o período, contudo, aconteceram várias mudanças nas raças prevalecentes na região (CARRIJO et al., 2003).

Vários caracteres foram observados no programa, mas o principal, foi sempre a produtividade de grãos. Há relatos de que esse caráter é um índice que envolve, praticamente, todos os outros (FERREIRA et al., 1995). Assim, as linhagens que se destacaram nos experimentos certamente tiveram fenótipos de interesse para outros caracteres, especialmente, resistência a patógenos. Esse 
fato pode ser constatado com a linhagem que originou a cultivar BRSMG Talismã. Durante o processo seletivo ela não foi avaliada especificamente para nenhum patógeno. Contudo, tem sido constatado que ela apresenta resistência a várias raças de Colletotrichum lindemuthianum, Phaeoisariopsis griseola e Uromyces appendiculatus (SOUZA et al., 2005). Evidencia-se assim, que as linhagens mais produtivas, em uma grande amplitude de ambientes, são aquelas que possuem, na sua constituição, alelos que conferem maior adaptação às condições de estresses abióticos e bióticos. No caso dos fatores bióticos, maior tolerância aos patógenos que ocorrem na cultura. Esse fato já foi comprovado com a resistência a Colletotrichum lindemuthianum no feijoeiro comum (ABREU et al., 2003).

Ficou evidenciado que as interações linhagens $x$ safras foram de maior magnitude que linhagens $\mathrm{x}$ anos (Figura 1). A importância da interação genótipos x safras na cultura do feijoeiro comum já foi constatada em outras oportunidades (RAMALHO et al., 1998; SILVA FILHO et al., 2002). Contudo, as interações linhagens x locais foram quase sempre superiores àquelas envolvendo safras e anos (Figura 2). Depreende-se que o programa deve dar ênfase em avaliar as linhagens no maior número de locais possível para melhorar a sua eficácia.

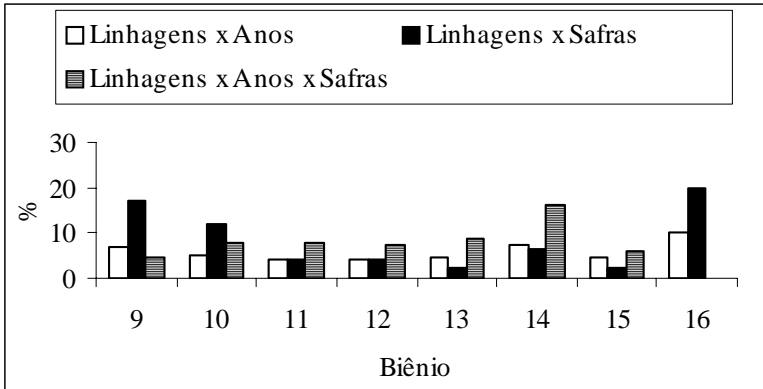

Figura 1 - Contribuição percentual $\left(\mathrm{R}^{2}\right)$ das diferentes interações envolvendo linhagens em relação à variação total. Dados dos experimentos conduzidos em Lavras, do $9^{\circ}$ ao $16^{\circ}$ biênio.

A proporção de linhagens com índice de confiança superior ao da ‘Carioca’ variou muito entre os biênios (Tabela 1). Entretanto, houve tendência de maior proporção de linhagens com índices de confiança superior a 100 com o decorrer do tempo. Esse último fato indica que foi possível, por meio da seleção, identificar linhagens com menor risco de adoção que a ‘Carioca’. Nesse contexto, é preciso salientar que a 'Carioca' apresenta tolerância acima da média a estresses abióticos, principalmente a fatores ligados à fertilidade do solo, tais como tolerância a alumínio, baixo fósforo e deficiência hídrica (FAGERIA, 1998; PIMENTEL \& PEREZ, 2000). Contudo, é susceptível à maioria das raças de Colletotrichum lindemuthianum (PEREIRA et al., 2004) e de Phaeoisariopsis griseola (MENDONÇA et al., 2003). Assim, é esperado que o seu desempenho sofra alterações em função da presença desses patógenos. Desse modo, a linhagem passa a apresentar menor risco que a 'Carioca' ao associar boa tolerância a estresses abióticos e resistência aos principais patógenos prevalecentes na cultura do feijoeiro comum. Fica evidenciado que, com o decorrer do processo seletivo, gradativamente tem sido possível obter linhagens que apresentam menor risco do que a 'Carioca'.

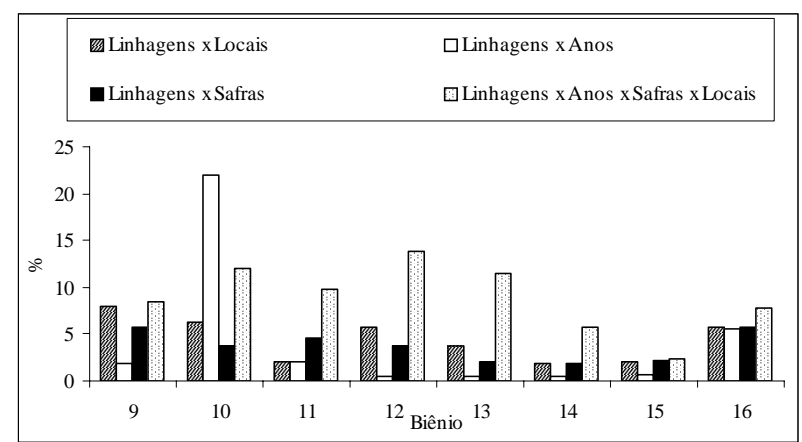

Figura 2 - Contribuição percentual $\left(\mathrm{R}^{2}\right)$ das diferentes interações em relação à variação total. Dados dos experimentos conduzidos em Lavras, Patos de Minas e Lambari, do $9^{\circ}$ ao $16^{\circ}$ biênio.

Como em todos os experimentos foi utilizada a 'Carioca' como testemunha, foi estimado o progresso genético em relação a essa cultivar (Tabela 2). Veja que as estimativas foram quase todas positivas e diferentes de zero. Esses valores do progresso genético são semelhantes aos relatados no Brasil, com outras metodologias envolvendo as culturas de feijão (FONSECA JÚNIOR, 1997; POMPEU, 1993), milho (ARIAS \& RAMALHO, 1998) e arroz (SOARES et al., 2005).

Pelas metodologias até então utilizadas, a ênfase foi na média geral das linhagens ou dos híbridos que estão sendo avaliados. No caso do milho, por exemplo, baseou-se no experimento de avaliação dos melhores híbridos de diferentes empresas. Portanto, as empresas já comercializavam ou tinham interesse de comercialização. No caso do experimento de linhagens elites da UFLA, o objetivo é o de identificar as melhores, para posterior avaliação no estado em competições com linhagens de outras instituições. Assim, o progresso genético deve ser considerado tendo como referência, por exemplo, as cinco melhores linhagens que são realmente as que possuem potencial para serem recomendadas. 
Tabela 1 - Percentagem das linhagens nos diferentes valores do índice de confiança em relação à cultivar Carioca, pela metodologia de Annicchiarico (1992), em diferentes períodos de avaliação.

\begin{tabular}{cccccc}
\hline Períodos de avaliação & -100 & $100-105$ & $105-115$ & $115-130$ & +130 \\
\hline $1974 / 1975$ & 84 & 5 & 5 & 5 & 0 \\
$1975 / 1976$ & 90 & 10 & 0 & 0 & 0 \\
$1976 / 1977$ & 38 & 13 & 19 & 31 & 0 \\
$1981 / 1982$ & 80 & 20 & 0 & 0 & 0 \\
$1982 / 1983$ & 6 & 22 & 39 & 17 & 17 \\
$1984 / 1985$ & 40 & 21 & 19 & 14 & 5 \\
$1985 / 1986$ & 90 & 5 & 5 & 0 & 0 \\
$1986 / 1987$ & 5 & 5 & 11 & 21 & 58 \\
$1989 / 1990$ & 8 & 40 & 20 & 32 & 0 \\
$1991 / 1992$ & 8 & 8 & 32 & 52 & 0 \\
$1992 / 1993$ & 14 & 17 & 47 & 19 & 3 \\
$1994 / 1995$ & 92 & 4 & 4 & 0 & 0 \\
$1996 / 1997$ & 42 & 19 & 36 & 0 & 3 \\
$1998 / 1999$ & 68 & 28 & 0 & 4 & 0 \\
$2000 / 2001$ & 68 & 28 & 4 & 0 & 0 \\
$2002 / 2003$ & 24 & 20 & 36 & 20 & 0 \\
$2003 / 2004$ & 19 & 28 & 44 & 8 & 0 \\
\hline
\end{tabular}

Tabela 2 - Estimativas do progresso genético (PG ) e do coeficiente de regressão linear (b) obtidos na média das cinco melhores linhagens considerando todos os ambientes (Geral), apenas em Lavras, e por safra envolvendo todos os ambientes.

\begin{tabular}{|c|c|c|c|c|c|}
\hline \multirow[b]{2}{*}{ Estimativas } & \multirow[b]{2}{*}{ Geral } & \multirow[b]{2}{*}{ Lavras } & \multicolumn{3}{|c|}{ Safras } \\
\hline & & & Águas & Secas & Inverno \\
\hline $\mathrm{b} / \mathrm{kgha}^{-1}$ biênio & 108,60 & 63,46 & 49,765 & 98,28 & $-51,41$ \\
\hline Probabilidade $\left(\mathrm{H}_{0}: \beta=0\right)$ & $<0,001$ & $<0,001$ & $<0,001$ & $<0,001$ & $<0,001$ \\
\hline $\mathrm{R}^{2} \%$ & 43,25 & 53,28 & 16,37 & 26,71 & 18,24 \\
\hline PG anual $\left(\mathrm{kg} \cdot \mathrm{ha}^{-1}\right)$ & 54,30 & 31,73 & 24,88 & 49,14 & $-25,71$ \\
\hline Média $\left(\mathrm{kg} \cdot \mathrm{ha}^{-1}\right)^{1}$ & 1245,95 & 974,68 & 1163,42 & 1607,78 & 3011 \\
\hline PG (\%/ano) & 4,36 & 3,26 & 2,14 & 3,06 & $-0,85$ \\
\hline
\end{tabular}

1/'Média estimada no primeiro biênio.

Questiona-se se o progresso genético seria maior no local em que as progênies foram obtidas e sempre avaliadas, como ocorrido no caso de Lavras. Nesse local, as linhagens foram obtidas e as progênies foram também avaliadas em outras condições, embora o ambiente de Lavras estivesse sempre presente. Ficou evidenciado que, de modo geral, as estimativas foram semelhantes. Assim, infere-se que o progresso genético pode ser extrapolado para outras condições.

A interação linhagens $\mathrm{x}$ safras evidenciou que o comportamento das linhagens não foi coincidente nas diferentes safras (Figura 2). Dessa forma, procurou-se verificar se o progresso genético diferiu entre as safras. Observou-se que não ocorreu progresso genético apenas 
quando se considerou a safra "de outono-inverno" (Tabela 2). Há algumas considerações a esse respeito. A primeira é a de que esta safra foi iniciada a partir do nono biênio, portanto, menor período que as safras "da seca" e "das águas". Uma outra explicação é a de que nessa safra praticamente não há estresse biótico. Como a vantagem das linhagens mais modernas é a incorporação de alelos de resistência, essa possível vantagem não se manifestou no trabalho realizado.

No Brasil, como já mencionado, existem poucos programas de melhoramento. Considerando a importância da cultura do feijoeiro comum, o número de melhoristas é ainda reduzido. $\mathrm{O}$ interesse das empresas privadas de sementes em ter os seus próprios programas de melhoramento é também pequeno. Assim, os programas do setor público, ou seja, das Universidades e da Embrapa e outras empresas estaduais, continuarão a ter a responsabilidade de obter novas linhagens que substituam com vantagens as pré-existentes. O programa de melhoramento da UFLA mostra que isso é possível e os poucos programas como esse existentes no país têm contribuído para que, mesmo com redução da área semeada nos últimos 21 anos, a produção dessa leguminosa ainda tenha aumentado no país (FAO, 2005).

\section{CONCLUSÕES}

Nos experimentos com a cultura do feijoeiro comum a contribuição da interação linhagens x locais para variação total é expressiva. Para atenuar o seu efeito os experimentos devem ser conduzidos em maior número de locais.

O programa de melhoramento genético da UFLA é eficiente e obtém linhagens com menor risco de adoção que a cultivar Carioca.

\section{REFERÊNCIAS BIBLIOGRÁFICAS}

ABREU, A. F. B.; RAMALHO, M. A. P.; GONÇALVES, F. M. A.; MENDONÇA, H. A. Utilização da produtividade de grãos na seleção para a resistência ao Colletotrichum lindemuthianum. Ciência e Agrotecnologia, Lavras, v. 27, n. 2, p. 363-369, abr./jun. 2003.

ABREU, A. F. B.; RAMALHO, M. A. P.; SANTOS, J. B.; MARTINS, L. A. Progresso do melhoramento genético do feijoeiro nas décadas de setenta e oitenta nas regiões Sul e Alto Paranaíba em Minas Gerais. Pesquisa Agropecuaria Brasileira, Brasília, v. 29, n. 1, p. 105-112, jan. 1994.

ALMEIDA, L. D. A.; LEITÃO FILHO, H. F.; MYASAKA, S. Características do feijão carioca, um novo cultivar. Bragantia, Campinas, v. 30, p. 33-38, abr. 1971. Nota 7.
ANNICCHIARICO, P. Cultivar adaptation and recomendation from alfafa trials in Northern Italy. Journal of Genetics and Plant Breeding, New Delhi, v. 46, n. 3, p. 269-278, 1992.

ARIAS, E. R. A.; RAMALHO, M. A. P. Progresso genético em milho no estado do Mato Grosso do Sul, no período de 1986/87 a 1993/94. Pesquisa Agropecuária Brasileira, Brasília, v. 33, n. 9, p. 1549-1554, set. 1998.

CARRIJO, F. R. F.; SOUZA, E. A.; RAMALHO, M. A. P. Common bean lines reaction to the anthracnose pathogen. Crop Breeding and Applied Biotechnology, Londrina, v. 3, n. 4, p. 297-300, Dec. 2003.

FAGERIA, N. K. Eficiência de uso de fósforo pelos genótipos de feijão. Revista Brasileira de Engenharia Agrícola e Ambiental, Campina Grande, v. 2, n. 2, p. 128131, maio/ago. 1998

FAO. Organização das Nações Unidas para a Agricultura e Alimentação. Disponível em: <http://faostat.fao.org/ faostat/form?collection=Production. Crops.Primary \& Domain $=$ Production $\&$ servlet $=1 \&$ hasbulk $=0 \&$ version $=$ ext\&language=ES>. Acesso em: 2 set. 2005.

FERREIRA, D. F.; RIBEIRO, F. E.; RAMALHO, M. A. P. Uso de índice de seleção no melhoramento do feijoeiro. Ciência e Prática, Lavras, v. 19, n. 1, p. 43-47, jan./mar. 1995.

FONSECA JÚNIOR, N. S. Progresso genético para a produtividade do feijão no estado do Paraná no período de 1977 a 1995. 1997. 211 f. Tese (Doutorado em Genética e Melhoramento de Plantas) - Escola Superior de Agricultura 'Luiz de Queiroz', Piracicaba, 1997.

MENDONÇA, H. A.; SANTOS, J. B.; RAMALHO, M. A. P. Genetic control of common bean reaction to angular leaf spot. Crop Breeding and Applied Biotechnology, Londrina, v. 3, n. 3, p. 209-216, Sept. 2003.

PEREIRA, H. S.; SANTOS, J. B.; ABREU, A. F. B. Linhagens de feijoeiro com resistência à antracnose selecionadas quanto a características agronômicas desejáveis. Pesquisa Agropecuária Brasileira, Brasília, v. 39, n. 3, p. 209-215, mar. 2004.

PIMENTEL, C.; PEREZ, A. J. C. Estabelecimento de parâmetros para avaliação de tolerância a seca em genótipos de feijoeiro. Pesquisa Agropecuária Brasileira, Brasília, v. 35, n. 1, p. 31-39, jan. 2000. 
POMPEU, A. S. Feijão. In: FURLANI, A. M. C.; VIEGAS, G. P. (Eds.). O melhoramento de plantas no Instituto Agronômico. Campinas: Instituto Agronômico, 1993. p. 111-156.

RAMALHO, M. A. P.; ABREU, A. de F. B.; SANTOS, P. S. J. Interação genótipos x épocas de semeadura, anos e locais na avaliação de cultivares de feijão nas regiões Sul e Alto Paranaíba em Minas Gerais. Ciência e Agrotecnologia, Lavras, v. 22, n. 2, p. 176-181, abr./jun. 1998.

SILVA FILHO, J. L.; RAMALHO, M. A. P.; ABREU, A. de F. B. A interação safra $x$ cultivares no trabalho dos melhoristas de feijão. In: CONGRESSO NACIONAL DE PESQUISA DE FEIJÃO, 7., 2002, Viçosa. Anais... Viçosa: UFV, 2002. p. 366-368.
SOARES, P. C.; MELO, P. G. S.; MELO, L. C.; SOARES, A. A. Genetic gain in improvement program of irrigated rice in Minas Gerais. Crop Breeding and Applied Biotechnology, Viçosa, v. 5, n. 2, p. 142-148, June 2005.

SOUZA, T. L. P. O. de; RAGAGNIN, V. A.; MELO, C. L. P. de; ARRUDA, K. M. A.; CARNEIRO, J. E. de S.; MOREIRA, M. A.; BARROS, E. G. de. Phenothypic and molecular characterization of cultivar BRSMG Talismã regarding the principal common bean pathogens. Crop Breeding and Applied Biotechnology, Viçosa, v. 5, n. 2, p. 247-252, June 2005.

VOYSEST, V. O. Mejoramento genético del frijol (Phaseolus vulgraris L.): legado de variedades de América Latina 1930-1999. Cali: Centro Internacional de Agricultura Tropical, 2000. $195 \mathrm{p}$. 